\title{
Escobar Chile, Luis Eudes. (2021). La toponimia en el norte de la región Puno. Esbozo para un análisis. Juliaca: Hijos de la Lluvia.
}

En una de sus egregias conferencias, el mayor lingüista vivo del mundo andino, Rodolfo Cerrón-Palomino, advertía del predominio de la toponimia popular en los Andes. Al mismo tiempo, apercibía del peligro de esta clase de onomástica en la configuración de falsas identidades lingüístico-culturales de la población andina como también del ocultamiento de la historia local y regional. Como se sabe, la toponimia es una evidencia de las ocupaciones y el dominio de un lugar por parte de un grupo social con lengua propia. En ese sentido, aunque parezca increíble, la toponimia es una disciplina científica transversal y multidisciplinaria. Se vincula con una gama de ciencias desde la lingüística, la filología hasta la historia, pasando por arqueología, historia, antropología, etnología, cartografía, geografía, etc.

Denominada también onomástica, la toponimia es una disciplina científica con metodología rigurosa y con un objeto estudio específico. Así, como toda ciencia, la toponimia analiza, describe y explica el nombre de los lugares: lagunas (limnónimos), ríos y riachuelos (hidrónimos) y montañas (orónimos). No obstante, más allá de estas definiciones académicas, la toponimia es una poética del espacio, por lo tanto, esas denominaciones son metáforas que representan a esos lugares.

El autor de La toponimia en el norte de la región Puno. Esbozo para un análisis es Luis Eudes Escobar. Él es natural de Puno egresado de la maestría en lingüística andina y educación de la Universidad Nacional del Altiplano (UNA) de Puno. Para optar el grado académico de dicha maestría, realizó una pesquisa sobre la toponimia en el norte de Puno. Y el libro que reseñamos es producto de mencionada investigación. Ha sido publicado en julio de este año con el sello del prestigioso grupo editorial Hijos de la Lluvia que dirige desde Juliaca-Puno Walter Bedregal. El contenido está organizado en seis apartados o capítulos.

En el primer capítulo, Escobar hace un marco general a las toponimias objeto de su estudio. En ese sentido, reconfigura la historia lingüística del altiplano puneño. Conforme a la lingüística histórica de Torero, Cerrón-Palomino, Hardman, Aldelaar y Van de Kerke, Escobar expone la presencia palmaria de las lenguas uru, puquina, aimara, quechua en Puno. Lo hace bajo la perspectiva de la 
glotocronología y la filología como cuando cita la famosa copia de curatos que un cura anónimo escribió para establecer las lenguas del altiplano a fin de que estas sirvan para hacer la predicación del cristianismo. Escobar va un poco más allá y expone la variación geográfica de las lenguas originarias que quedan en el mismo Puno. Siguiendo la perspectiva de Cerrón-Palomino, Luis Eudes Escobar retoma el quechumara y su paralelismo morfosintáctico. Esta exposición de la presencia de lenguas originarias en el Altiplano no es casual, pues páginas después hará uso de esta información para el análisis de los topónimos.

En el segundo capítulo, el investigador puneño expone todo el marco teórico o estado de arte de la toponimia. Para tal efecto recurre al famoso tratadista de esta disciplina, el filólogo español Maximiano Trapero y su clásico manual Para una teoría lingüistica de la toponimia. Apela también a los peruanos Cerrón-Palomino y Solís Fonseca. En este apartado, clasifica los estudios toponímicos en los Andes en coloniales y modernos para terminar en «Estudios toponímicos en Puno».

En el tercer capítulo, Escobar recurre a la geografía descriptiva. Lo hace con el fin de ubicar científicamente al espacio geográfico de su investigación. Este es el Fundo San Antonio de Caque, ubicado en la comunidad campesina de Cerro Minas, distrito de Ucuviri, provincia de Lampa, región Puno. Además de las características geográficas del lugar, expone la flora y fauna del mencionado fundo.

En el cuarto capítulo, el autor del libro que reseñamos expone todo el corpus toponímico de su pesquisa. Se trata de una sistematización por sectores del fundo San Antonio. Clasifica los topónimos en documentados y no documentados. Los documentados son aquellos que anteriormente han sido tratados y expuestos en documentos y, los no documentados aquellos nuevos topónimos que aún no han sido estudiados.

El quinto capítulo, que es el capítulo medular, está destinado al análisis lingüístico de los topónimos que integran el corpus. Para ello, recurre a los procedimientos morfofonológicos y sintácticos. De la misma forma, acude también a la lexicosemántica y a la filología. Su análisis lo acompaña con citas: sea para reforzar su análisis o para refutar los que erróneamente han sido propuestos.

En el sexto capítulo, el investigador realiza una clasificación de los topónimos analizados. Dicha tipificación corresponde a las lenguas del altiplano expuestos en el primer capítulo. Los resultados arrojan lo siguiente: categorías quechuas, categoría aimara, categoría puquina, categoría mixta, categoría cultural y los exónimos. El capítulo concluye con unos alcances para una clasificación por categorías geográficas. 
En la parte final, el libro se cierra con cuatro apéndices y una extensa y pertinente bibliografía. Los apéndices son fotografías, documentos antiguos escaneados, mapas y otros.

En su arte poética denominado El arco y la lira, el poeta mexicano Octavio Paz elucida:

Todo periodo de crisis se inicia o coincide con una crítica del lenguaje. [...] No sabemos en dónde empieza el mal, si en las palabras o en las cosas, pero cuando las palabras se corrompen y los significados se vuelven inciertos el sentido de nuestros actos y de nuestras obras también es inseguro. (2003, p. 29)

Podemos inferir de esta cita perteneciente al premio nobel de literatura, que, con el tiempo, los vocablos sufren cambios. Esas modificaciones pueden obscurecer la historia local y generar identidades inciertas y actos inciertos. El trabajo toponímico y sus resultados son la luz que otorga certeza, cuando los vocablos se han corrompido.

El libro La toponimia en el norte de la región Puno. Esbozo para un análisis es una de las mejores publicaciones del siglo xxi en materia lingüística en los Andes. No solo es un listado de los topónimos y su escueta «interpretación» al costado. Es realmente un despliegue de conocimiento y destreza en el análisis toponímico. No es la clásica toponimia popular basada en el sonido y desde la visión quechuocéntrica muy practicada en los Andes. El libro con el cual el maestro Cerrón-Palomino estaría a gusto. Es una contribución no solo a la lingüística del altiplano, sino también es un libro que pretende ser una luz en la historia del distrito de Ucuviri, pueblo natal del autor. Escobar actualiza y retoma, en su mencionado libro, la importancia de la toponimia para la historia y la identidad lingüístico-cultural de los pueblos. Confirma, asimismo, esa clásica apotegma de la toponimia: «Los hombres pasan, los nombres quedan».

Niel Palomino Gonzales

Universidad Nacional de San Antonio Abad del Cusco nielpalomino@yahoo.com

\section{Referencias bibliográficas}

Paz, O. (2003). El arco y la lira. Fondo de Cultura Económica. 


\section{Trayectoria académica del autor}

Niel Palomino Gonzales es licenciado en Lengua y Literatura por la UNSAAC, magíster en Educación por la Universidad Nacional Mayor de San Marcos, Magister Scientiae en LINGÜística ANDINA por la Universidad Nacional del Altiplano - Puno. Candidato a doctor en Ciencias de la Educación por la Universidad Nacional de Educación Enrique Guzmán y Valle. Es docente en la Universidad Nacional de San Antonio Abad del Cusco y de la Universidad Andina del Cusco.

Ha publicado el poemario Cantar del amante labriego (2002), los libros de cuentos Cantar del Wakachuta y otros cuentos (2010) y Todavía somos (2018), el poemario T’aniwi, poesía quechua de vanguardia (2019), el libro de ensayos El fuego del placer textual, glosas sobre las literaturas peruanas (2020), entre otros textos de lectura, redacción y ortografía. Tiene en preparación su tercer libro de cuentos.

Ha obtenido las siguientes distinciones:

- Primera Mención Honrosa del Premio Regional de Cultura, modalidad cuento en español, 2007.

- Primera Mención Especial del Premio Nacional de Literatura en lenguas originales, 2020. 